\title{
Evaluation of enzymatic hydrolysis via alcoholic fermentation of corn flour
}

\author{
Md. Shahriar Rahaman Shams ${ }^{1}$, Fahriha Nur-A Kabir ${ }^{2}$, Tajnuba Sharmin ${ }^{3 *}$, Mohammad Gulzarul Aziz
}

${ }^{1}$ M.S in Food Engineering, Bangladesh Agricultural University Mymensingh-2202

${ }^{2}$ Lecturer, NPI University of Bangladesh Manikgonj-1800

${ }^{3}$ Lecturer, NPI University of Bangladesh Manikgonj- 1800

${ }^{4}$ Professor, Bangladesh Agricultural University Mymensingh-2202

*Corresponding Author email: itstajnuba@gmail.com

\section{Doi: 10.2478/mjhr-2019-0013}

\begin{abstract}
:
The research was concerned with the enzymatic hydrolysis followed by alcoholic fermentation of corn flour. Commercial corn flour purchased from local market contained starch of $87.25 \%$, moisture $11.86 \%$ and ash $0.70 \%$. The kinetics of corn flour hydrolysis was performed at $50^{\circ} \mathrm{C}, 65^{\circ} \mathrm{C}$ and $80^{\circ} \mathrm{C}$ using commercial thermos table- $\infty$-amylase and $\infty$-amyloglucosidase. During hydrolysis the residual starch content was decreased with increasing hydrolysis time. The line weaver- Burk plot for enzyme hydrolysis of corn starch for $2.5 \%, 5 \%$ and $10 \%$ flour solution showed a Km value of $2.46,2.27$ and $1.73 \mathrm{mg} / \mathrm{ml}$ and Vmax values $1.23,1.21$ and $0.96 \mathrm{U} / \mathrm{ml}$ for $50^{\circ} \mathrm{C}, 65^{\circ} \mathrm{C}$ and $80^{\circ} \mathrm{C}$ respectively. Thin layer chromatography (TLC) was used to detect the presence of dextrose in the hydrolyzates. The Rf (Retention factors) values showed that the starch was mainly composed of dextrose and depended on carrier solvent use for dextrose assessment. When $100 \%$ ethyl alcohol used as carrier solvent the Rf value was 0.72 and ethyl alcohol: ethyl acetate= $1: 1$ the Rf value was 0.65. Both corn flour solution and its enzymatic hydrolysates were fermented with commercial baker's yeast. Both the cases starch content was decreased and alcohol content was increased during hydrolysis and alcohol production was 3 times more from hydrolysates. The results obtained here will be useful for further research in the production of other value added products like white vinegar from the produced alcohol from con flour.
\end{abstract}

Keywords: Alcoholic Fermentation, Enzymatic Hydrolysis, Kinetics, Residual Starch and Substrate Concentration.

\subsection{Introduction:}

Starch is one of the most abundant renewable carbohydrate reserves in a large variety in cereals. It is a polymer of glucose, and mainly consists of amylose and amylopectin. Amylose is a mostly linear molecule containing $\alpha$-d-glucosyl units that are essentially linked by $\alpha-1,4$-glycosidic bonds, whereas amylopectin is a highly branched structure composed of large polymers of $\alpha$-1,4-glycosidic bonds linked $\alpha$-d-glucosyl units with $\alpha$-1, 6-linked side [15].

Starch is the second most important and abundant source of carbon and energy in plants, and thus has large market demand and many applications in industry. It can be used to produce many valuable food products in the food processing industry, such as maltose, glucose, fructose, glucose-fructose syrups, organic acids, amino acids, etc [17]. The hydrolysis of starch can be achieved by three methods, Acid, Acid-Enzyme or Enzyme-Enzyme hydrolysis. Recently acid hydrolysis has been replaced by enzymatic hydrolysis because it required the use of corrosion resistant materials gave rise to high color and salt ash and requires more energy for heating [12].

The Enzyme - Enzyme hydrolysis is the most advanced industrial enzyme application in the food industry and is one of the most successful enzyme technologies. Various grains may be used as a source of enzyme during the hydrolysis of starch to glucose [9]. The activity of amylase using starch as substrate method is simple in use for determining the period of germination for favorable amylase activity in extracts of maize malt crude for production of maltose syrup. The timing for the decolourisation of standard acid permanganate solution obtained by the released glucose showed the activity amylase enzyme. Increasing glucose concentrations resulted in decreasing decolourisation times and this was seen in the standard plot of the decolourisation of an acidified permanganate solution by standard glucose solutions.

The Fermentation Industries Section of IUPAC (International Union of Pure and Applied Chemistry) found that the divergent ways of expressing alcohol content, and particularly the use of mutually incomparable units, have led to a great deal of confusion and misinterpretation. They developed the standardization of the methods for determination of the alcohol content as well as the drawing up of alcohol tables. It was decided that a standardized method should be presented for the determination of the alcohol content at $20^{\circ} \mathrm{C}$, and that an alcohol table for use with this method should be prepared on the basis of the densities of alcohol—water solutions determined [10].

Corn is the third most important cereal after rice and wheat in Bangladesh. Its production is increasing at approximately $20 \%$ per year since early 1990 . Maize has versatile use both as food and feed. Currently, major part of maize produced in Bangladesh is used as feed. For any biotechnological process cheap source of raw materials is pre-requisite and corn could be the best candidate considering its current production for the process of glucose or alcohol and white acetic acid production. It will help to diversify the use of grown corn.

The following main objectives were drawn to carry out the investigation:

a. To assess the effects of substrate concentration and temperature on the kinetics of corn flour hydrolysis.

b. To compare alcohol production from corn flour and its hydrolysis with commercial yeast

\subsection{Materials and methods}

\subsection{Sample and Chemical Collection}

Corn flour collected from Kamal Ronozit Market (KR) of BAU campus. 100\% Ethanol, 100\% methanol, Ethyl acetate, Pure glucose, Hydrochloric acid, sodium chloride, $\alpha$-amylase and $\alpha$-glucosinodase from megazyme, sulfuric acid, sodium hydroxide, iodine, distilled water etc reagents were collected from laboratory stock. All the chemicals are analytical grade with the highest purity.

\subsection{Experimental design}

This study was carried out according to the following experimental design (Schematic):

\author{
Collection of samples (corn flour)
}

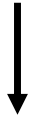

Determination of moisture

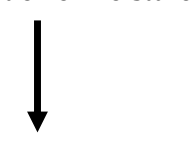




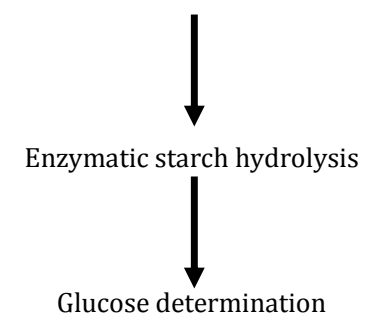

\section{Alcoholic fermentation}



Figure 1: Schematic illustration of the experimental design

\subsection{Proximate Analysis}

The proximate analysis of moisture was carried out by using Ranganna methods (2003) and ash was determined by using AOAC standard methods [2]. Starch was determination by adopting Megazyme (2016).

\subsection{Enzymatic starch hydrolysis}

The enzymatic starch hydrolysis was determination by adopting Megazyme (2016). At first three conical fluxes washed with distilled water. Then $2.5 \mathrm{gm}, 5$ gm and $10 \mathrm{gm}$ samples were taken in the conical flux and added distilled water to make the volume $100 \mathrm{ml}$. The conical fluxes were kept in the water bath at $50 \mathrm{o}, 65 \mathrm{o} \mathrm{C}$ and $80 \mathrm{o}$ C. Immediately $100 \mu \mathrm{L}$ of thermostable $\alpha$-amylase and $\alpha$-glucosinodase enzymes were added with proper stirring. The conversion of starch into glucose was monitored by using a refractometer. TSS reading was taken at every 15 minutes interval.

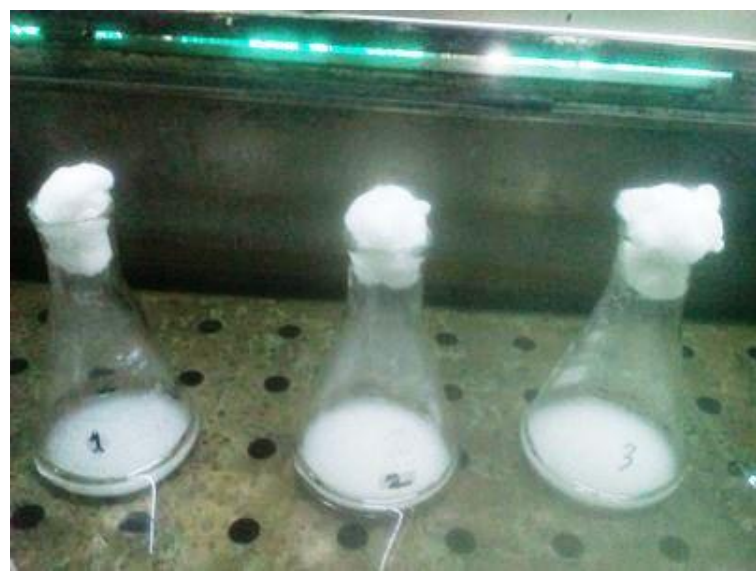

(a) Solution before hydrolysis

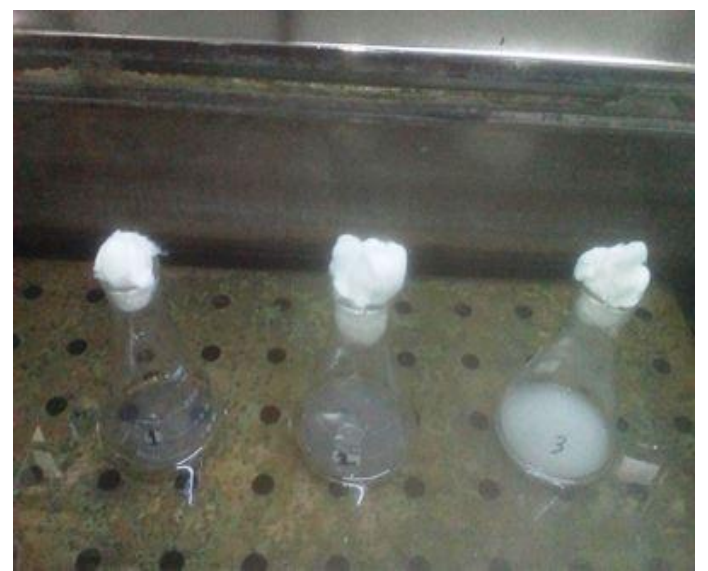

(b) Solution after hydrolysis

Figure 2: Corn flour starch hydrolysis

\subsection{Glucose determination by thin layer chromatography}

Total solid, ash, structural carbohydrates, and pretreated biomass were determined using Laboratory analytical procedures (LAP) as reported by [13].

\subsubsection{Preparation of solution}

$2.5 \%, 5 \%$, and $10 \%$ standard glucose solution and $2.5 \%, 5 \%$ and $10 \%$ concentration of starch hydrolyzed solution were prepared.

\subsubsection{Preparation of the spotting}

The powdered side of the silica gel plate, not the shiny, plastic side was the side that was spotted. The plates were of such a size that only three spots can be run on each. A fresh capillary tube was used for each spot. Each spot was made as small as possible (less than about $1 \mathrm{~mm}$ diameter). After applying the spots were checked under the UV lamp to see that they were of a reasonable size. The UV light must be held close to the plate to see the spots. If the spot was too much large, a new plate will be prepared. If a spot was too small, more solution will be added.

\subsubsection{Preparation of the migration solvent}

The mobile phase was poured into the TLC chamber to a leveled few centimeters above the chamber bottom. A moistened filter paper in mobile phase was placed on the inner wall of the chamber to maintain equal humidity (and also thereby avoids edge effect this way). Now the plate prepared with sample spotting was placed in TLC chamber so that the side of the plate with the sample line was facing the mobile phase. Then the chamber was closed with a lid. The plate was then immersed, such that the sample spots were well above the level of mobile phase for development. The migration solvent was constituted by $100 \%$ ethyl alcohol and ethyl acetate: ethyl alcohol $=1: 1[1]$. 
faint. The plate was then placed into a jar containing iodine crystals for a few minutes. The iodine jar was keep capped and in the fume hood. The spots were appearing different from those shown with UV light. The iodine method must be done after the UV method because the compounds were reacting with the iodine, possibly changed the results [5].

\subsubsection{Execution of TLC}

The deposits samples and sugar controls were performed using syringes on Silica gel plates (60F254 of $20 \times 20 \mathrm{~cm}(\mathrm{Merck} \mathrm{KgaA})$ of $0.25 \mathrm{~mm}$ thick), the diameters were not exceeded $2 \mathrm{~mm}$ and were placed vertically in the tank. Glucose positions were revealed by the chemical developer. The retention factors (Rf) were calculated according to the formula:

\section{$\mathrm{Rf}=\mathrm{C} / \mathrm{S} ; \mathrm{S}=$ Solvent front; $\mathrm{C}=$ Center of spot; $\mathrm{Rf}=$ Retentions factor}

\subsection{Alcoholic fermentation}

Twenty-two (22) gm flour was taken in a washed beaker and poured into $300 \mathrm{ml}$ water and mixed properly. The solution was slightly warmed and added $\alpha$-amylase and $\alpha$-glucosinodase enzyme of $1.5 \mathrm{ml}$ of each for starch hydrolysis. After proper starch hydrolysis, $0.45 \mathrm{gm}$ baker's yeast powder was added with stirring. Then the total soluble solids (TSS) and specific gravity were determined for measuring the alcohol formation.

\subsubsection{Specific gravity}

A pycnometer was cleaned and dried, and noted the weight (W1). The stopper and the cap were removed and filled it with the sample. Wipe the outside surface thoroughly, weight accurately, and noted the weighted (W2). The volume of pycnometer was $50 \mathrm{ml}$.

\section{Specific gravity $=\frac{\text { Weight of pycnometerwith sample- Weight of empty pycnometer }}{\text { Volume of pycnometer }}$}

$$
=\frac{\mathrm{W} 1-\mathrm{W} 2}{50}
$$

\subsubsection{Alcohol Determination by Specific Gravity}

The method assumes that the difference in Specific Gravity before and after fermentation is due solely to the conversion of sugars before fermentation into alcohol after fermentation.

The method relies on -

$\%(\mathrm{v} / \mathrm{v})$ alcohol $=(\mathrm{SG} 2-\mathrm{SG} 1) / 0.0074$

Where - SG1 is the initial specific gravity measurement; SG2 is the final specific gravity measurement.

\subsection{Results and Discussion}

\subsection{Proximate analysis of Corn flour}

Commercial corn flour purchased from local market was analyzed for starch, moisture and ash content. The results obtained are presented in Table 1 below:

Table 1. Proximate analysis of Corn flour

\begin{tabular}{|l|l|l|}
\hline Parameter & Corn flour (wb) & Corn flour (db) \\
\hline Starch & $87.25 \%$ & $100 \%$ \\
\hline Moisture & $11.86 \%$ & $13.79 \%$ \\
\hline Ash & $0.70 \%$ & $0.80 \%$ \\
\hline Total & 99.81 & - \\
\hline
\end{tabular}

The major fraction of corn flour is starch and water, which contributed 99.11\%. Among these two components starch represented the major part (87.25\%) followed by moisture content (11.86\%) whereas ash contributed only $0.70 \%$ (wet basis). Nevertheless, minor amount $(0.19 \%)$ of other compounds and only $0.11 \%$ of other macro compounds also present in corn flour. The same compounds in dry basis in the flour were presented in the same Table. Among the other macromolecules, they could be minor amount of protein and fat. The study is nearly agreement with the findings of Earle et al. (1946).They reported that starch, which accounts for approximately $68-74 \%$ of a mature kernel by weight, and moisture content is the primary source of stored energy in corn. Haibo Huang (2013) reported that the moisture content of matured corn was $21.3 \%$.

\subsection{Corn flour hydrolysis}

\subsubsection{Effect of substrate concentration on residual corn flour starch during hydrolysis}

Three different concentrations of corn flour were hydrolyzed with commercial enzymes and degree of hydrolysis with time was measured by measuring residual starch using centrifugation. The residual starch content during hydrolysis is presented in Figure 3. 




Figure 3: Degree of corn flour starch hydrolysis

In corn flour starch hydrolysis, the degree of starch hydrolysis was increased with increasing time since residual starch content was decreased with the time of hydrolysis. Starch hydrolysis was rapid during first 30 minutes. After 30 minutes those graphs show linearly and approach to zero until fail at light concentration. At low concentration the hydrolysis rate was higher than that of at high concentration as shown in Figure 3 . For $2.5 \%$ flour solution the residual starch content came close to zero $(0.108 \mathrm{gm})$ after 90 minutes of hydrolysis. For $5 \%$ and $10 \%$ flour solutions the residual starch contents were $0.218 \mathrm{gm}$ and 0.435 , respectively after 90 minutes of hydrolysis. With increasing substrate concentration, residual starch content was also increased for a fixed hydrolysis time. At low substrate concentration the residual starch content in the final hydrolysates was low. It means that at this concentration active site of enzymes is still unsaturated with substrate or the product concentration is not enough to inhibit the enzyme activities for hydrolysis. The same phenomena were observed for corn flour concentration of $5 \%$. However, in case of $10 \%$ flour concentration the residual starch content is rather higher. The reason could be either substrate-enzyme saturation or product inhibition. At this substrate concentration the product formation (dextrose) is more than $9 \%$ which is sufficiently higher compared to that of found at $2.5 \%$ and $5 \%$ flour concentration. The results of current work are similar with the findings of Vasanthy et al., (1993). They reported that the corn flour $(16 \% \mathrm{w} / \mathrm{w})$ was hydrolysed with alpha-amylase and glucoamylase, the concentration of glucose obtained $1 \mathrm{hr}$ was $11.9 \%(\mathrm{w} / \mathrm{w})$ and 2 and $3 \mathrm{hr}$ was $13.1 \%(\mathrm{w} / \mathrm{w})$. At those interval starch hydrolysis was $90.2 \%, 99.2 \%$ and $99.2 \%$ respectively.

\subsubsection{Effect of substrate concentration and temperature on TSS hydrolysates}

Corn flour solution presents zero TSS before hydrolysis and TSS increased progressively with hydrolysis time. By using thermostable $\alpha$-amylase and $\alpha$ glucosinodase enzyme the starch hydrolyzed into dextrose so that the total soluble solids (TSS) were increased. Hence, TSS of the hydrolysates was monitored during hydrolysis at different temperature and the results are shown in Figure 4 during hydrolysis at temperature $50^{\circ} \mathrm{C}$.

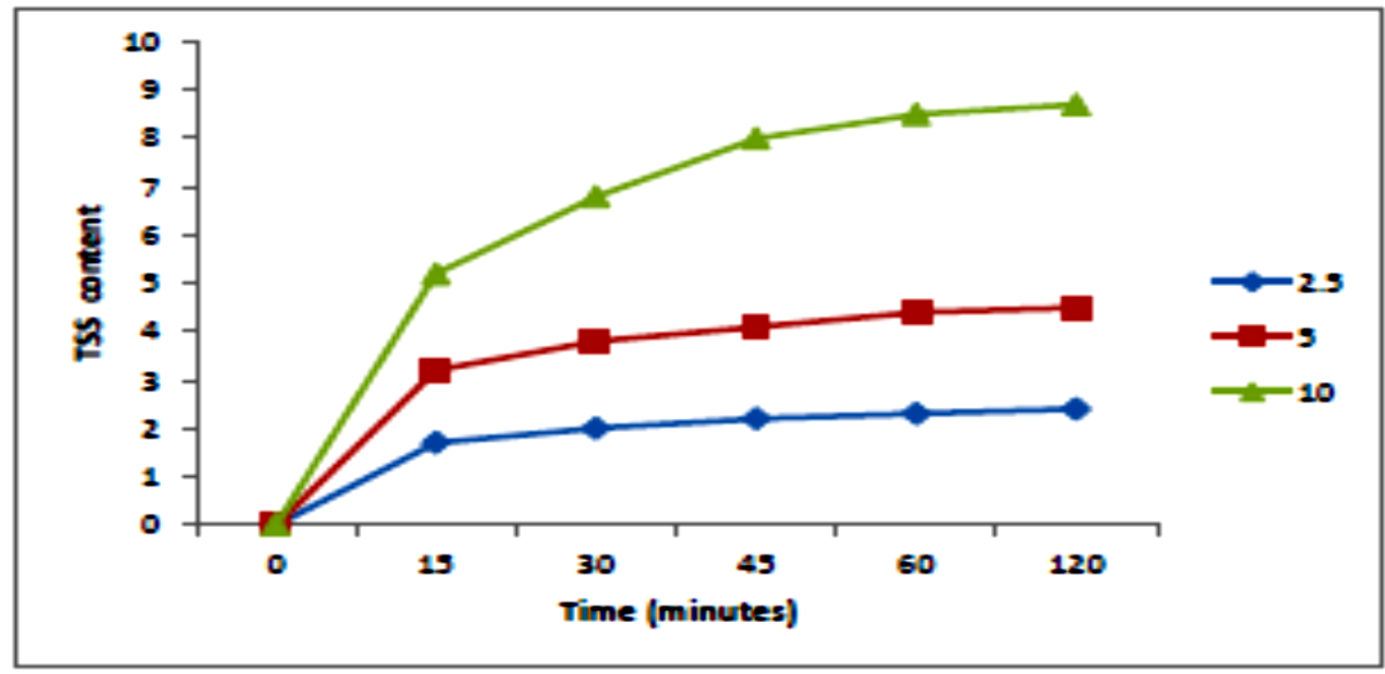

Figure 4: Kinetics of starch hydrolysis at $50^{\circ} \mathrm{C}$

During starch hydrolysis the total soluble solids (TSS) was increased with time irrespective of substrate concentration. Right after onset of the reaction, the rate of TSS change was rapid up to $15 \mathrm{~min}$ and then it showed minor changes up to end of the reaction studied.

As it is expected, the higher flour concentration in the reaction mixture gave the higher TSS changes. As shown in Figure 4, hydrolysates obtained from $10 \%$ flour solution gave the highest TSS (8.7\%) followed by $5 \%$ flour solution and the lowest TSS (2.2\%) showed by $2.5 \%$ flour hydrolysates. It was also observed that reaction was continued up to the end at somehow faster rate in case of $10 \%$ flour concentration. But in case of $2.5 \%$ and $5 \%$ concentration, reaction came to almost equillibrium at early period of reaction (i.e., after $15 \mathrm{~min}$ ). 


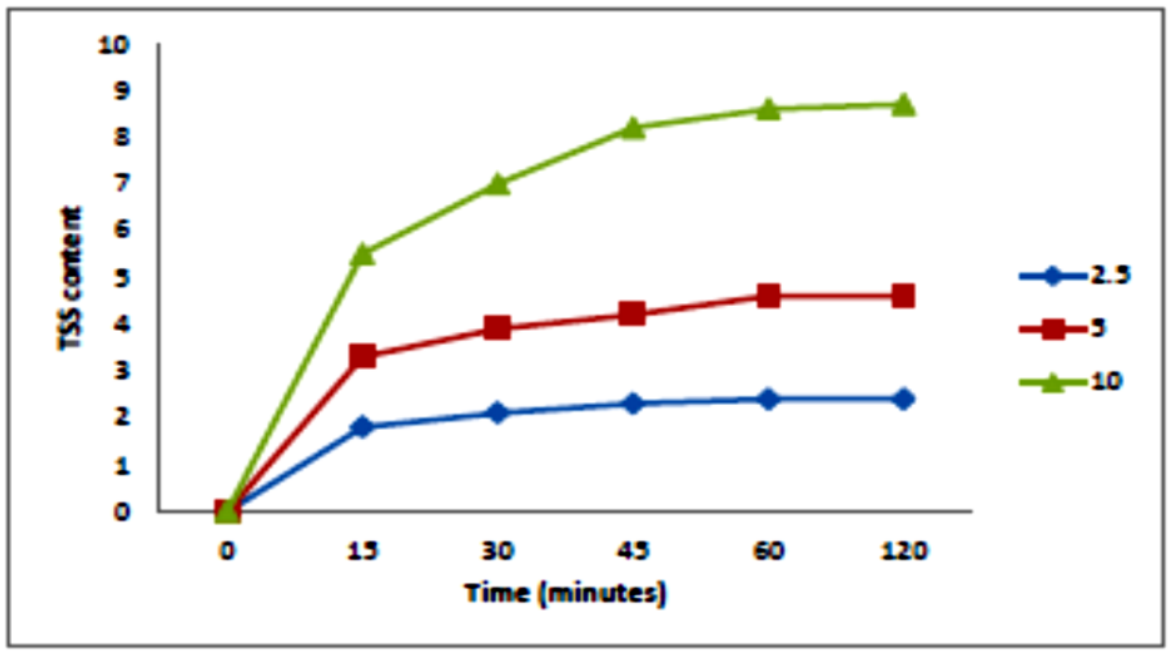

Figure 5: Kinetics of starch hydrolysis at $65^{\circ} \mathrm{C}$

In case of the corn flour hydrolysis at $65^{\circ} \mathrm{C}$, the hydrolysis trend and rate were observed the same as that of at $50^{\circ} \mathrm{C}$. The changes of TSS during hydrolysis at $65^{\circ} \mathrm{C}$ are given in Figure 5. The TSS of the final hydrolysates due to hydrolysis at $65^{\circ} \mathrm{C}$ was marginally varied with that of at $50^{\circ} \mathrm{C}$. As shown in Figure 5 , hydrolysis was rapid up to 15 minutes and it was higher for higher flour concentration (2.5\% and $5 \%)$ and then it showed almost stable. However, at higher flour concentration $(10 \%)$ reaction was still higher beyond the initial rate.

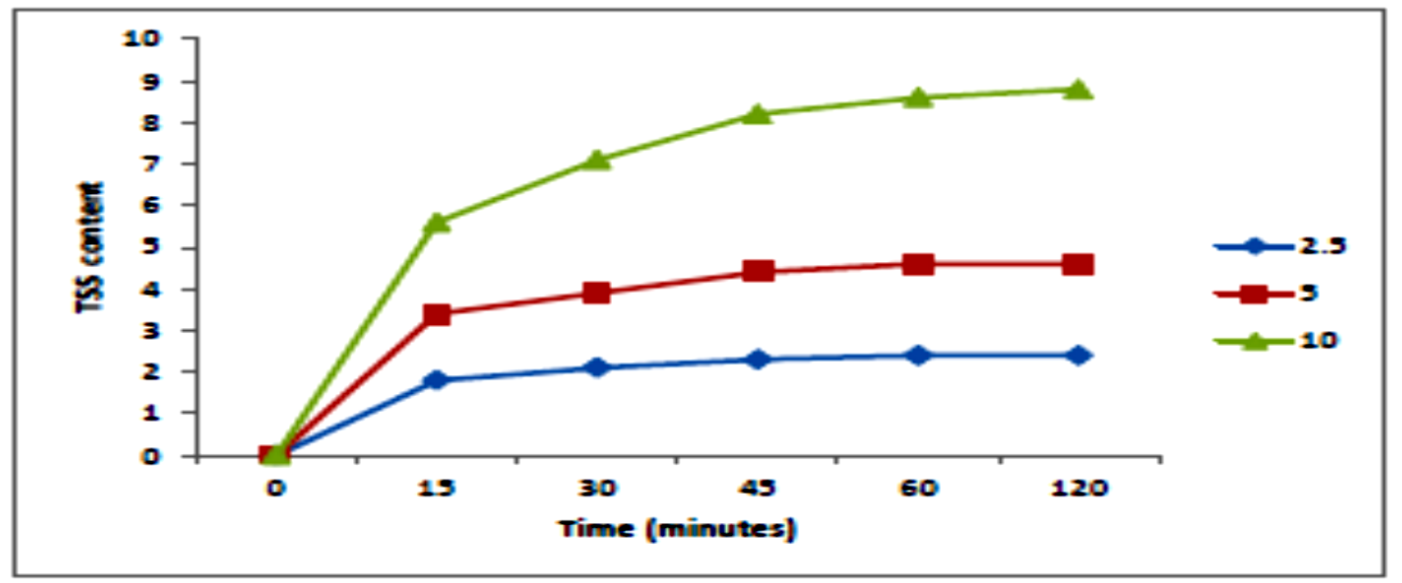

Figure 6: Kinetics of starch hydrolysis at $80 \mathrm{o} C$

In case of hydrolysis at $80^{\circ} \mathrm{C}$, similar pattern in comparison of at $50^{\circ} \mathrm{C}$ and $65^{\circ} \mathrm{C}$ was observed. The changes of TSS of the hydrolysates during hydrolysis are presented in Figure 6 .

Initially the total soluble solids (TSS) were increased rapidly. But with the time the rate of change of total soluble solids (TSS) became slow as like as presented in 4 and 5 . However, final TSS of the hydrolysates at $80^{\circ} \mathrm{C}$ was slightly higher that of at 50 and $65^{\circ} \mathrm{C}$. Temperature effects on the rate of flour starch hydrolysis were marginally varied. In case of $80^{\circ} \mathrm{C}$ product formation rate was slightly higher compared to at 50 and $65^{\circ} \mathrm{C}$. It is obvious that at high temperature the enzyme activated fast so that the starch hydrolyzis would also faster. In our case the temperature effect is quite marginal. The reason could the thermostability of commercial enzymes. The enzymes collected from then Megazyme is highly thermostable $\left(100^{\circ} \mathrm{C}\right)$ and hence reaction conducted at temperature below $100^{\circ} \mathrm{C}$ had little effect on the activation of the enzyme. Initially the starch hydrolysis rate was faster and accordingly the total soluble solids (TSS) were increased faster. It could be due to low product concentration in the hydrolysates.

\subsubsection{Determination of $\mathrm{Km}$ and Vmax of enzyme activity from starch hydrolysis:}

The $\mathrm{K}_{\mathrm{m}}$ and $\mathrm{V}_{\max }$ values as influenced by substarte concentration and reaction temperatures were claculated and presented in Figure 7 to 9 .The activity of enzyme increased from 0.113 to $0.373 \mathrm{u} / \mathrm{ml} / \mathrm{min}$ with increasing the substrate concentration from 0.25 to $1.0 \mathrm{mg} / \mathrm{ml}$ and was found maximum activity at $1.0 \mathrm{mg} / \mathrm{ml}$ and further increase in substrate concentration above the optimum level would not produce any increase in the enzyme activity. It is happened when residual substrate is reached too low to continue further reaction.
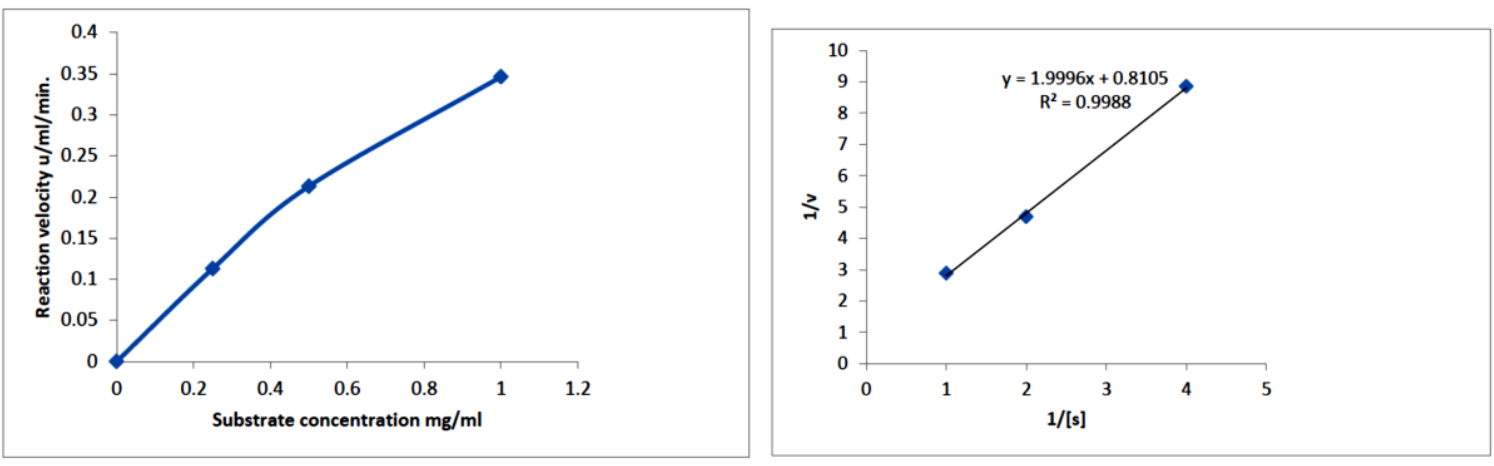
Figure 7: Effect of substrate concentrations and Lineweaver-burk plot for the hydrolysis of starch by enzyme activity at $50^{\circ} \mathrm{C}$


Figure 8: Effect of substrate concentrations and Lineweaver-burk plot for the hydrolysis of starch by enzyme activity at $65^{\circ} \mathrm{C}$
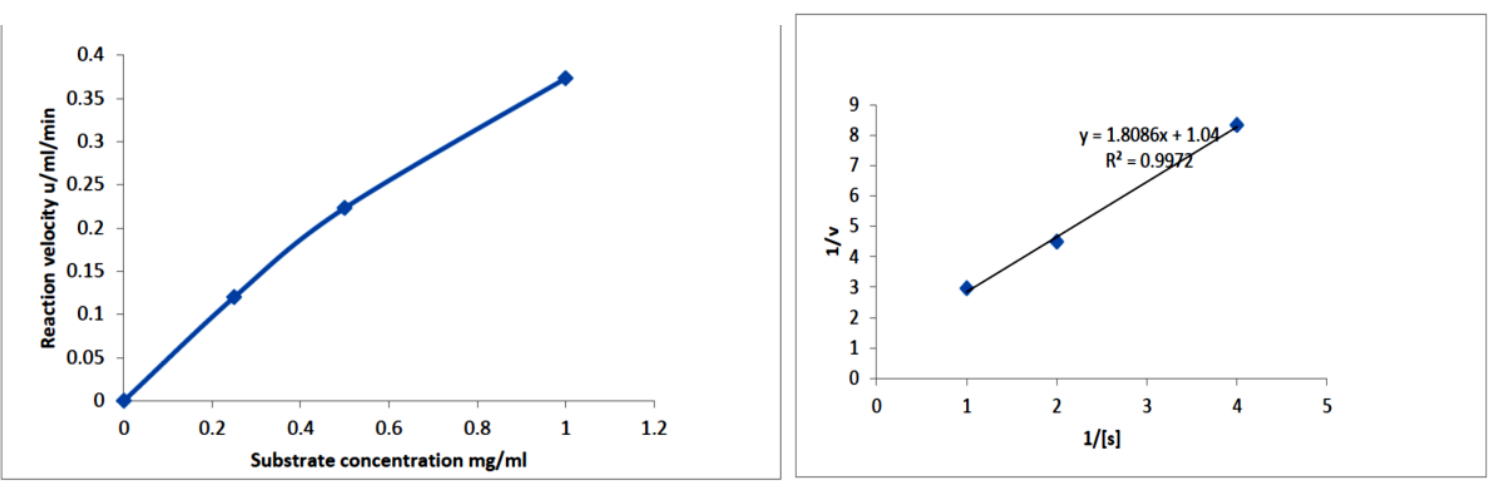

Figure 9: Effect of substrate concentrations and Lineweaver-burk plot for the hydrolysis of starch by enzyme activity at 80o C

The lineweaver-Burk plot for enzyme for corn starch hydrolysis for 2.5\%, 5\%and $10 \%$ flour concentration showed a Km value of 2.46 , 2.27 and 1.73 for $50^{\circ} \mathrm{C}, 65^{\circ} \mathrm{C}$ and $80^{\circ} \mathrm{C}$ and also Vmax values were $1.23,1.21$, and $0.96 \mathrm{U} / \mathrm{ml}$ for $50^{\circ} \mathrm{C}, 65^{\circ} \mathrm{C}$ and $80^{\circ} \mathrm{C}$ respectively. The results of current work are similar with the findings of Tapan et al. (2005). They reported that the $\mathrm{Km}$ value was $1.96 \mathrm{mg} / \mathrm{ml}$ and Vmax value was $1.42 \mathrm{U} / \mathrm{ml}$ in starch hydrolysis. The results of current work are also similar with the findings of Arotupin et al. (2008). They reported that the activity of enzyme produced by Aspergillus repens increased with increase in substrate concentration reaching maximum at $4 \mathrm{mg} / \mathrm{ml}$ and the lineweaver-Burk plot for the hydrolysis of pectin indicated approximately $1.3 \mathrm{mg} / \mathrm{ml}$

\subsection{Glucose determination by TLC}

TLC revealed the presence of glucose composition from the corn starch at difference percentage with different temperature. To identify the glucose presence TLC was performed. The single spot on TLC can be identified as glucose. Rf value confirmed the purity of glucose content. The Rf values showed that the starch was mainly composed of glucose. The Rf value is depended on carrier solvent use for glucose determination is shown Table 2.

Table 2. Rf value of glucose in different carrier solvent

\begin{tabular}{|c|c|}
\hline Carrier solvent & Rf value $^{\circ}$ \\
\hline Ethyl alcohol (100\%) & 0.74 \\
\hline Ethyl alcohol : Ethyl acetate(50:50) & 0.65 \\
\hline
\end{tabular}

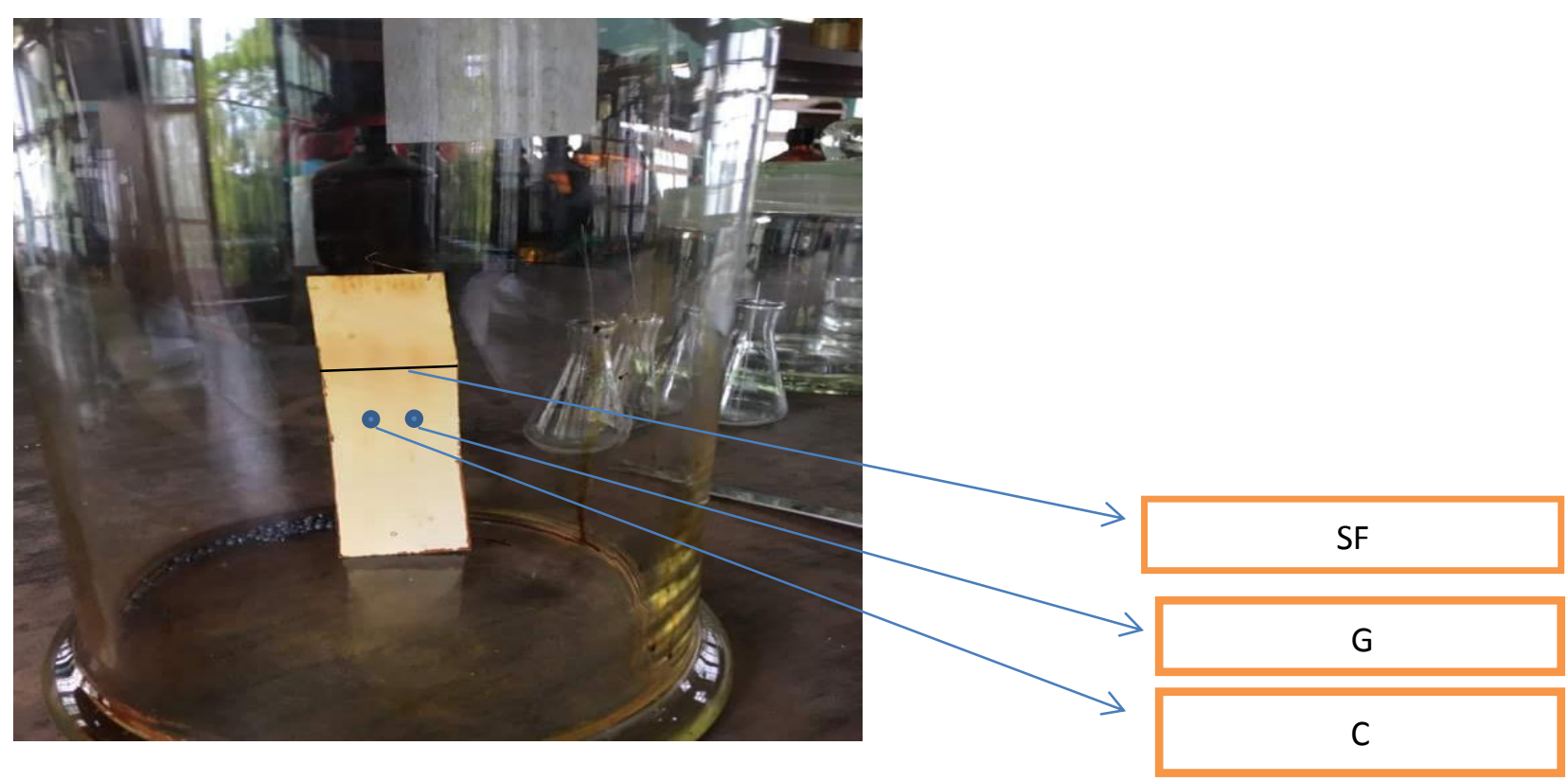

Figure 10: Determination of Rf value from glucose sample 
$\mathrm{SF}=$ Solvent front; $\mathrm{G}=\mathrm{Glucose} ; \mathrm{C}=$ Center of spot

For both the solvents the calculated Rf values for the hydrolysates were almost similar as shown in Table 2 and the distance moved by the pure glucose and the hydrolysates in the similar level as shown in Figure 10.

Retention factors are useful in comparing the results of one chromatogram to the results of another. If the conditions in which the chromatograms are run are unchanged the retention factor for a given material should remain constant. This allows unknowns to be compared to known materials. If the retention factor of an unknown does not match that of a known material, they are not the same compound. Similar retention factors suggest that the two samples could be the same, but is not proof. In reality, the retention factors will vary slightly from sample to sample. Interactions of the individual components with each other and the concentration of the component in the sample will both affect the Rf value.

If the same grade of Chromatography medium is used and the room temperature of the experiment does not fluctuate too much, the remaining critical variable to be observed is the amount of dye spotted. Large amounts tend to form elongated zones with uneven distribution of dye along its zone. Too much dilute spots makes visibility of separated dye poor.

The presence of glucose composition from the corn starch at difference percentage with different temperature was determined by thin layer chromatography (TLC). The starch was mainly composed of glucose was calculated by Rf value. The Rf value was depended on solvent nature. When $100 \%$ ethyl alcohol used as carrier solvent the Rf value was 0.74 of glucose and ethyl alcohol: ethyl acetate $=1: 1$ the Rf value of glucose was 0.65 .

The results of current work are similar with the findings of Ido et al. (1978). They reported that in silica gel plate the solvent of Ethyl acetate: Ethyl alcohol=1:1 the Rf value was 0.67 .

\subsection{Alcoholic fermentation of corn flour hydrolysates}

Corn flour hydrolysates were fermented into alcohol by using commercial yeast and the conversion corn flour hydrolsates into alcohol was monitored by measuring the specific gravity of the solution. Insoluble corn starch flour became rather transparent solution after enzymatic hydrolysis. Fermentation of corn flour hydrlysate with commercial yeast converts dextrose into alcohol.

\subsubsection{TSS and Specific gravity determination}

During alcohol production the total soluble solids (TSS) was decreased and the specific gravity was increased during the course of fermentation. The changes of TSS and alcohol are shown in Figure 11.


Figure 11: TSS reducing and increasing the alcohol during production of alcohol from glucose sample.

During alcohol production the total soluble solids (TSS) was decreased with time. Initially the rate of TSS change was rapid and then it showed minor changes up to end of the reaction studied. On the other hand the alcohol production was increased with time. Right after onset of the reaction, the rate of alcohol production was faster and then it showed slow changes up to end of the reaction. Fermentation of corn flour solution without enzymatic hydrolysis was also carried out and the kinetics of alcohol production is presented in Figure 12.



Figure 12: Determination of alcohol of the starch sample in different time 
Without enzymatic hydrolysis the alcohol production from corn flour was too low. The alcohol production was slowly increased, which came to equilibrium at the end of reaction studied is shown in Figure 12.

Finally $3.24 \%$ of alcohol $(\mathrm{w} / \mathrm{v})$ was produced from $7.5 \%$ corn starch solution by using enzymatic hydrolysis and $1.081 \%$ (w/v) alcohol was produced without enzymatic hydrolysis. The result showed that the rate of alcohol production by using enzyme was 3 times more than without enzymatic hydrolysis. The study is nearly agreement with the findings of Mita et al., (1987). They reported that $5.0 \%$ starch solution produced $2.3 \%$ alcohol (w/v) and $10 \%$ starch solution produced $4.48 \%$ alcohol $(\mathrm{w} / \mathrm{v})$

\subsection{Conclusion}

To achieve the above specific objectives, moisture content of corn flour is important because of selection of flour for starch hydrolysis. The corn flour contained high amounts of starch and water and minor amount of other compounds including ash (0.7\%). The residual starch was measured using centrifugation and used to assess the degree of hydrolysis in different concentrations of corn flour with commercial enzymes. The low substrate concentration resulted in the low residual starch. The highest residual starch was exhibited by the $10 \%$ flour starch hydrolysates. It could be due to either enzyme substrate saturation or the inhibition of the enzyme activity by the product concentration formed during hydrolysis. During starch hydrolysis the total soluble solids (TSS) was increased with time irrespective of substrate concentration. Right after onset of the reaction, the rate of TSS change was rapid and then it showed minor changes up to end of the reaction studied.

The Km and Vmax values were mostly influenced by substarte concentration and slightly affected by thereaction temperatures. The lineweaver-Burk plot for enzymatic starch hydrolysis for different substrate concentration showed different Km values at different temperatures. Sugar composition of polysaccharide was found by thin layer chromatography (TLC). The Rf value is depended on carrier solvent used for glucose determination. By using commercial yeast corn flour hydrolysates were fermented into alcohol and the conversion of corn flour hydrolsates into alcohol was monitored by measuring the specific gravity of the solution. In conclusion, starch hydrolysis into glucose by enzyme is very important for many processing industries. Alcohol production in short time with low cost and low labor from corn flour is also very effective on industrial purpose. The results obtained here will be useful for further research in the production of other value added products like white vinegar form the produced alcohol from corn flour. For better improvement further studies is essential in this connection

\subsection{Acknowledgement}

This research work was financially supported by National Science and Technology (NST) under the ministry of Science and Technology, Bangladesh.

\section{References}

[1] A. Ghebregzabher, M. Rufins, Monaldi, and B. Lamtom, "Thin layer chromatography of carbohydrates", J Chromatographic, 127, 133-162, 1976.

[2] AOAC, "Official methods of Analysis of Analytical Chemists", 18th edition, Washington DC, USA, 2005.

[3] D.J. Arotupin, F.A. Akinyosoye, and A.K. Onifade, "Purification and characterization of pectin methyl esterase from aspergillus repens isolated from cultivated soil”, African J. of Biotechnology, 7, 1991-1998, 2008.

[4] F.R. Earle, J.J. Curtis, and J.E. Hubbard, “Composition of the component parts of the corn kernel”, J. Cereal chemistry, 23, 504-511, 1946.

[5] K.V. Giri, and V.N. Nigam, "Separation of simple saccharides and oligosaccharides by circular paper chromatography”, J. Nature wissenschaften, 40, 343, 1953.

[6] H. Haibo, "Characterization of chemical composition, milling properties and carbon dioxide diffusivity resulting from early harvest corn and corn stover, University of Illinois at Urbana-Champaign. Department of Agricultural and Biological Engineering", University of Illinois. Urbana, Illinios, 2013.

[7] Ido, C.N. Wan, V. Casella, J.S. Fowler, A.P. Wolf, M. Reivich, and D.E. Kuhl, "Labeled 2-deoxy-D-glucose analogs. F-labeled 2-deoxy-2-fluoro-D-glucose, 2deoxy-2-fluoro-D-mannose and 14C-2-deoxy-2-fluoro-D-glucose", J Technological Society of Starch, 3, 314-422, 1978.

[8] B. Mita, D. Sipra, and S.K. Majumdar, "Production of Alcohol from Starch by Direct Fermentation”, J Technological Society of Starch, 11: 213-236, 1987.

[9] U.G. Mohammed, B.M. Abu, and D.E. Effiong, "A Kinetic Study of the Enzymatic Hydrolysis of Cassava Starch", International Journal of Science and Engineering Investigations, 1, 181-196, 2012.

[10] Osborne, E.C. McKelvy, and H.W. Bearce, “J of Research of the National Bureau of Standards”, 9, 327, 1913.

[11] S. Ranganna, "Hand Book of Analysis of Quality Control for fruit and vegetable products. Second edition, New Delhi, India", Tata McGraw Hill production Company Limited, New Delhi. pp: 4-30, 2003.

[12] R.D.N. Silva, F.P. Quintino, V.N. Monteiro, and E.R. Asquieri, “Production of glucose and fructose syrups from cassava (ManihotesculentaCrantz) starch using enzymes produced by microorganisms isolated from Brazilian Cerrado soil", Technology Aliment, 30, 27-31, 2010.

[13] A. Sluiter, B. Hames, D. Hyman, C. Payne, R. Ruiz, C. Scarlata, J. Sluiter, D. Templeton, and J. Wolfe, "Determination of total solids in biomass and total dissolved solids in liquid process samples", J of Agriculture and Food Chemistry, 58, 90432-9053, 2005.

[14] K.D. Tapan, J. Malabendu, R.P. Priti, and B. Tanmay, "The Effect of Temperature, pH, and Salt on Amylase in Heliodiaptomusviduus viduus (Gurney) (Crustacea: Copepoda: Calanoida)", Turkish J of Zology, 30, 187-195, 2005.

[15] V. Vamadevan, and E. Bertoft, "Structure-function relationships of starch components", J. of Food Science and Technology, 67, 55-68, 2015.

[16] A. Vasanthy, and B. Kandiah, "Hydrolysis of Macromolecules in corn flour and filterability", J. of the Science Society of Thailand, 19, 37-45, 1993.

[17] J. Waterschoot, S.V. Gomand, E. Fierens, and J.A. Delcour, "Production, structure, physicochemical and functional properties of maize, cassava, wheat, potato and rice starches", J. of Food Science and Technology, 67, 14-29, 2015.

\section{Appendices}

Table A.1. Moisture content determination of corn flour

\begin{tabular}{|c|c|c|}
\hline Sample & Moisture Content (per gm) & Average (\%) \\
\hline 1 & 0.1189 & 11.86 \\
\cline { 1 - 2 } 2 & 0.1192 & \\
\hline 3 & 0.1181 & \\
\hline
\end{tabular}


Table A.2. Ash Content determination of corn flour

\begin{tabular}{|c|c|c|}
\hline Sample no & Ash content per gm & Average (\%) \\
\hline 1 & 0.70 & 0.70 \\
\hline 2 & 0.67 & \\
\hline 3 & 0.72 & \\
\hline
\end{tabular}

Table A.3. Starch present in corn flour (wet content)

\begin{tabular}{|c|c|c|}
\hline Sample (1 gm starch) & Starch Content & Average (\%) \\
\hline 1 & 0.8728 & \\
\hline 2 & 0.8717 & \\
\hline 3 & 0.8730 & \\
\hline
\end{tabular}

Table A.4. Residual starch content with the time of hydrolysis

\begin{tabular}{|c|c|c|c|}
\hline Time (minutes) & \multicolumn{3}{|c|}{ Residual Starch (gm) } \\
\hline & $2.5 \%$ & $5 \%$ & $10 \%$ \\
\hline 30 & 0.108 & 0.218 & 0.435 \\
\hline 60 & 0.061 & 0.131 & 0.268 \\
\hline 90 & 0.011 & 0.028 & 0.062 \\
\hline
\end{tabular}

Table A.5. Enzymatic starch hydrolysis at $50^{\circ} \mathrm{C}$

\begin{tabular}{|c|c|c|c|}
\hline Time (minutes) & $2.5 \%$ & $5 \%$ & $10 \%$ \\
\hline 0 & 0 & 0 & 0 \\
\hline 15 & 1.7 & 3.2 & 5.2 \\
\hline 30 & 2 & 3.8 & 8.8 \\
\hline 45 & 2.2 & 4.1 & 8.5 \\
\hline 60 & 2.3 & 4.4 & 8.7 \\
\hline 120 & 2.4 & 4.5 & 8 \\
\hline
\end{tabular}

Table A.6. Enzymatic starch hydrolysis at $65^{\circ} \mathrm{C}$

\begin{tabular}{|c|c|c|c|}
\hline Time (minutes) & $2.5 \%$ & $5 \%$ & $10 \%$ \\
\hline 0 & 0 & 0 & 0 \\
\hline 15 & 1.8 & 3.3 & 5.5 \\
\hline 30 & 2.1 & 3.9 & 8.2 \\
\hline 45 & 2.3 & 4.2 & 8.6 \\
\hline 60 & 2.4 & 4.6 & 8.7 \\
\hline 120 & 2.4 & 4.6 & 7 \\
\hline
\end{tabular}

Table A.7. Enzymatic starch hydrolysis at $80^{\circ} \mathrm{C}$

\begin{tabular}{|c|c|c|c|}
\hline Time (minutes) & $2.5 \%$ & $5 \%$ & $10 \%$ \\
\hline 0 & 0 & 0 & 0 \\
\hline 15 & 1.8 & 3.4 & 5.6 \\
\hline 30 & 2.1 & 3.9 & 7.1 \\
\hline 45 & 2.3 & 4.4 & 8.2 \\
\hline 60 & 2.4 & 4.6 & 8.6 \\
\hline 120 & 2.4 & 4.6 & 8.8 \\
\hline
\end{tabular}

Table A.8. Effect of substrate concentration on enzymatic starch hydrolysis at $80^{\circ} \mathrm{C}$

\begin{tabular}{|c|c|c|}
\hline Substrate conc. (\%) & Substrate conc. [S] (Mg/ml) & Activity or reaction velocity (U/ml/min) \\
\hline 0 & 0 & 0 \\
\hline 0.025 & 0.25 & 0.127 \\
\hline 0.050 & 0.5 & 0.223 \\
\hline 0.1 & 1.0 & 0.373 \\
\hline
\end{tabular}


Table A.9. Data for $\mathrm{K}_{\mathrm{m}}$ value determination at $80^{\circ} \mathrm{C}$

\begin{tabular}{|c|c|}
\hline $\mathrm{X}(1 /[\mathrm{s}])$ & $\mathrm{Y}(1 / \mathrm{v})$ \\
\hline 4 & 7.87 \\
\hline 2 & 4.49 \\
\hline 1 & 2.96 \\
\hline
\end{tabular}

Table A.10. Effect of substrate concentration on enzymatic starch hydrolysis at $65^{\circ} \mathrm{C}$

\begin{tabular}{|c|c|c|}
\hline Substrate conc. (\%) & Substrate conc. [S] (Mg/ml) & Activity or reaction velocity (U/ml/min) \\
\hline 0 & 0 & 0 \\
\hline 0.025 & 0.25 & 0.12 \\
\hline 0.050 & 0.5 & 0.222 \\
\hline 0.1 & 1.0 & 0.367 \\
\hline
\end{tabular}

Table A.11. Data for $\mathrm{K}_{\mathrm{m}}$ value determination at $65^{\circ} \mathrm{C}$

\begin{tabular}{|c|c|}
\hline $\mathrm{X}(1 /[\mathrm{s}])$ & $\mathrm{Y}(1 / \mathrm{v})$ \\
\hline 4 & 8.33 \\
\hline 2 & 4.54 \\
\hline 1 & 2.72 \\
\hline
\end{tabular}

Table A.12. Effect of substrate concentration on enzymatic starch hydrolysis at $50^{\circ} \mathrm{C}$

\begin{tabular}{|c|c|c|}
\hline Substrate conc. (\%) & Substrate conc. $[\mathrm{S}](\mathrm{Mg} / \mathrm{ml})$ & Activity or reaction velocity (U/ml/min) \\
\hline 0 & 0 & 0 \\
\hline 0.025 & 0.25 & 0.113 \\
\hline 0.050 & 0.5 & 0.213 \\
\hline 0.1 & 1.0 & 0.346 \\
\hline
\end{tabular}

Table A.13. Data for $\mathrm{K}_{\mathrm{m}}$ value determination at $50^{\circ} \mathrm{C}$

\begin{tabular}{|c|c|}
\hline $\mathrm{X}(1 /[\mathrm{s}])$ & $\mathrm{Y}(1 / \mathrm{v})$ \\
\hline 4 & 0.94 \\
\hline 2 & 0.469 \\
\hline 1 & 0.289 \\
\hline
\end{tabular}

Table A.14. TSS and specific gravity for alcohol production from glucose sample

\begin{tabular}{|c|c|c|c|}
\hline Time(minutes) & Total soluble solid (TSS) & Specific gravity (Difference) & Alcohol (ml) \\
\hline 6 & 6.5 & 0.06 & $0.81 \%$ \\
\hline 24 & 5 & 0.013 & $1.75 \%$ \\
\hline 48 & 4 & 0.018 & $2.43 \%$ \\
\hline 72 & 3.2 & 0.022 & $2.97 \%$ \\
\hline 96 & 3 & 0.024 & $3.24 \%$ \\
\hline
\end{tabular}

Table A.15. TSS and specific gravity for alcohol production from glucose sample

\begin{tabular}{|c|c|c|}
\hline Time(minutes) & Specific gravity (Difference) & Alcohol (ml) \\
\hline 6 & 0.003 & $0.40 \%$ \\
\hline 24 & 0.005 & $0.67 \%$ \\
\hline 48 & 0.007 & $0.94 \%$ \\
\hline 72 & 0.008 & $1.081 \%$ \\
\hline 96 & 0.008 & $1.081 \%$ \\
\hline
\end{tabular}

\section{Equation A.1}

The retention factors $\left(\mathrm{R}_{\mathrm{f}}\right)$ were calculated according to the formula: $\mathrm{R}_{\mathrm{f}}=\mathrm{C} / \mathrm{S} ; \mathrm{S}=$ Solvent front; $\mathrm{C}=$ Center of spot; $\mathrm{R}_{\mathrm{f}}=$ Retentions factor 
Specific gravity $=\frac{\text { Weight of pycnometerwith sample- Weight of emptypycnometer }}{\text { Volume of pycnometer }}$

Volume of pycnometer

$$
=\frac{\mathrm{W} 1-\mathrm{W} 2}{50}
$$

\section{Equation A.3}

Alcohol Determination by Specific Gravity:

$\%(\mathrm{v} / \mathrm{v})$ alcohol $=(\mathrm{SG} 2-\mathrm{SG} 1) / 0.0074$

Where :

SG1 is the initial specific gravity measurement;

SG2 is the final specific gravity measurement. 